\title{
Activation of microglia induces symptoms of Parkinson's disease in wild-type, but not in IL-1 knockout mice
}

\author{
Sachiko Tanaka ${ }^{1 *}$, Atsuko Ishii ${ }^{1}$, Hirokazu Ohtaki ${ }^{2}$, Seiji Shioda ${ }^{2}$, Takemi Yoshida ${ }^{1}$ and Satoshi Numazawa ${ }^{1}$
}

\begin{abstract}
Background: Parkinson's disease (PD) is an age-related progressive neurodegenerative disorder caused by selective loss of dopaminergic neurons from the substantia nigra (SN) to the striatum. The initial factor that triggers neurodegeneration is unknown; however, inflammation has been demonstrated to be significantly involved in the progression of PD. The present study was designed to investigate the role of the pro-inflammatory cytokine interleukin-1 (IL-1) in the activation of microglia and the decline of motor function using IL-1 knockout (KO) mice.

Methods: Lipopolysaccharide (LPS) was stereotaxically injected into the SN of mice brains as a single dose or a daily dose for 5 days $(5 \mathrm{mg} / 2 \mathrm{ml} /$ injection, bilaterally). Animal behavior was assessed with the rotarod test at $2 \mathrm{hr}$ and 8,15 and 22 days after the final LPS injection.

Results: LPS treatment induced the activation of microglia, as demonstrated by production of IL-1 $\beta$ and tumor necrosis factor (TNF) a as well as a change in microglial morphology. The number of cells immunoreactive for 4-hydroxynonenal (4HNE) and nitrotyrosine (NT), which are markers for oxidative insults, increased in the SN, and impairment of motor function was observed after the subacute LPS treatment. Cell death and aggregation of a-synuclein were observed 21 and 30 days after the final LPS injection, respectively. Behavioral deficits were observed in wild-type and TNFa KO mice, but IL-1 KO mice behaved normally. Tyrosine hydroxylase (TH) gene expression was attenuated by LPS treatment in wild-type and TNFa KO mice but not in IL-1 KO mice.
\end{abstract}

Conclusions: The subacute injection of LPS into the SN induces PD-like pathogenesis and symptoms in mice that mimic the progressive changes of PD including the aggregation of a-synuclein. LPS-induced dysfunction of motor performance was accompanied by the reduced gene expression of TH. These findings suggest that activation of microglia by LPS causes functional changes such as dopaminergic neuron attenuation in an IL-1-dependent manner, resulting in PD-like behavioral impairment.

Keywords: Microglia, IL-1 $\beta$, Knockout mouse, Neuroinflammation, Parkinson's disease

\section{Background}

Lipopolysaccharide (LPS) is a bacterial endotoxin known to stimulate immune responses [1]. In in vivo experiments, LPS activates the microglia, resulting in the release of inflammatory cytokines such as interleukin-1 $\beta$ (IL-1 $\beta$ ) and tumor necrosis factor $\alpha$ (TNF $\alpha)$, which contribute to neurodegeneration [1-5]. Activation of the microglia

\footnotetext{
* Correspondence: stanaka@pharm.showa-u.ac.jp

'Department of Pharmacology, Toxicology and Therapeutics, Division of Toxicology, School of Pharmacy, Showa University, 1-5-8 Hatanodai,

Shinagawa-ku, Tokyo 142-8555, Japan

Full list of author information is available at the end of the article
}

has also been observed during the development of neurodegenerative conditions such as Alzheimer's disease (AD), Parkinson's disease (PD) and multiple sclerosis [6-8]. Several epidemiological studies have shown that non-steroidal anti-inflammatory drugs are associated with a reduced risk of developing PD [9-11]. These phenomena suggest that inflammation is implicated in neurodegenerative diseases [12]. PD is an age-related progressive neurodegenerative disorder caused by the selective loss of dopaminergic neurons from the substantia

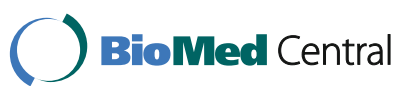

(c) 2013 Tanaka et al.; licensee BioMed Central Ltd. This is an open access article distributed under the terms of the Creative Commons Attribution License (http://creativecommons.org/licenses/by/2.0), which permits unrestricted use, distribution, and reproduction in any medium, provided the original work is properly cited. 
nigra (SN) to the striatum [13]. However, the initial factor that triggers neurodegeneration is unknown. PD animal models have been created by exposing animals to chemical toxins such as 1-methyl 4-phenyl 1,2,3,6,tetrahydropyridine (MPTP) [14-16] and 6-hydroxydopamine (6-OHDA) [17]. These toxins selectively modulate dopaminergic neurons via the uptake by the dopamine transporter. However, these animal models do not encompass all the prevailing pathologies of PD. Therefore, we designed a PD animal model where there is neuroinflammation in the mouse brain. In our previous studies, we demonstrated that subacute administration of LPS $(20 \mu \mathrm{g} / 2 \mu \mathrm{L} /$ injection, daily, bilaterally for 5 consecutive days) into the CA1 region of the rat and mouse hippocampus activated the microglia and increased production of IL-1 $\beta$ and TNF $\alpha$, concomitantly resulting in learning and memory deficits in the animals as assessed using a step-through passive avoidance test $[5,18]$. These results suggest that inflammation affects neuronal function. Furthermore, IL-1 $\beta$ plays an important role in LPS-induced impairment of learning and memory using IL-1 $\alpha / \beta$ knockout (KO) mice [18]. In the present study, we modified the regimen and obtained evidence that suggests there are PD-like pathological changes and symptoms in the animal model. In addition, LPS-induced microglial activation causes toxicity in dopaminergic neurons in an IL-1-dependent manner. The results of the present study may lead to a better understanding of the roles of IL-1 in the activation of the microglia and the mechanisms underlying neurodegenerative diseases.

\section{Methods}

\section{Materials}

The following reagents were obtained from commercial sources: LPS (from Escherichia coli serotype 055:B5; L2880, endotoxin level $3000000 \mathrm{EU} / \mathrm{mg}$ ), monoclonal antimouse glial fibrillary acidic protein (GFAP) antibody from Sigma-Aldrich (St Louis, MO), monoclonal goat antimouse CD11b antibody from Serotec Ltd (Oxford, UK), goat anti-murine IL-1 $\beta$ antibody from R\&D Systems (Minneapolis, MN), polyclonal rabbit anti-Iba1 antibody from Wako Pure Chemical Industries (Osaka, Japan), polyclonal anti-3-nitrotyrosine antibody, Alexa Fluor 546 donkey anti-goat IgG antibody, Alexa Fluor 488 goat anti-rat IgG antibody and Alexa Fluor 488 goat anti-mouse IgG antibody from Molecular Probes (Eugene, OR), monoclonal anti- $\alpha$-synuclein antibody from Santa Cruz Biotechnology, Inc (Dallas, TX), polyclonal anti-4-hydroxynonenal (4HNE) antibody from ENZO Life Sciences, Inc (Famingdale, NY) and antinitrotyrosine (NT) antibody from Merck (Darmstadt, Germany). All other chemicals were of analytical or the highest grade commercially available.

\section{Animals, surgical operations and LPS treatment}

All animal experiments were conducted in accordance with the Showa University Animal Experiment and Welfare Regulations. The IL-1 KO male mice, carrying a null mutation in both the IL- $1 \alpha$ and IL- $1 \beta$ genes, and the TNFa KO male mice were established by Horai et al. [19] and Tagawa et al. [20], respectively. Male BALB/c mice were purchased from Sankyo Laboratory Service (Tokyo, Japan). The mice (at 9 to 10 weeks old) were anesthetized with sodium pentobarbital $(50 \mathrm{mg} / \mathrm{kg}$ intraperitoneally) and immobilized in a stereotaxic frame. Two guide cannulas were implanted and used to inject LPS into both sides of the substantia nigra pars reticulata (SNR) $(2.92 \mathrm{~mm}$ posterior, $1.25 \mathrm{~mm}$ lateral and $4.95 \mathrm{~mm}$ ventral to the bregma). These cannulas were fixed to the skull with dental cement. Eight days after surgery, the mice were injected bilaterally with either LPS $(5 \mu \mathrm{g})$ dissolved in $2 \mu \mathrm{L}$ of phosphate-buffered saline (PBS) or PBS alone under isoflurane anesthesia. Acute treatment with PBS or LPS ( $5 \mu \mathrm{g} / 2 \mu \mathrm{L} /$ injection, bilaterally) was carried out to study the immunohistochemistry of the microglia. Subacute PBS or LPS injections ( $5 \mu \mathrm{g} / 2 \mu \mathrm{L} /$ injection, bilaterally) were administered daily for 5 consecutive days under isoflurane anesthesia. These animals were used for behavioral tests, gene expression experiments and to study the immunohistochemistry of the brain section.

\section{Behavioral analysis: the rotarod test}

Motor coordination was assessed with a rotating rod apparatus (Panlab Harvard Apparatus, Barcelona, Spain). The rod was $3 \mathrm{~cm}$ in diameter. The mice were placed on the rod when it was rotating at $4 \mathrm{rpm}$. The rotation speed was increased from 4 to $40 \mathrm{rpm}$ within $5 \mathrm{~min}$. The latency was recorded for each animal. This is the time (in seconds) before they fall. Each mouse was tested three times and the median time of the three trials was calculated. The results are expressed as the mean \pm standard error of the mean (SEM) in each group.

\section{Immunohistochemistry}

Six hours after acute LPS or PBS treatment, the mice were anesthetized with pentobarbital and were perfused transcardially with saline followed by $0.1 \mathrm{M}$ phosphate buffer ( $\mathrm{PB}, \mathrm{pH}$ 7.2) containing $2 \%$ paraformaldehyde [21]. The brains were removed and immersed for 1 day in $0.1 \mathrm{M}$ PB containing $2 \%$ paraformaldehyde and then for 2 days in $0.1 \mathrm{M} \mathrm{PB}$ containing $20 \%$ sucrose. The brains were then embedded in a mixture of $20 \%$ sucrose in $0.1 \mathrm{M} \mathrm{PB}$ and Tissue Teck (2:1; Miles Inc, Elkhart, IN), frozen on dry ice, and stored at $-80^{\circ} \mathrm{C}$ until studied. Subsequently, $10 \mu \mathrm{m}$ sections were cut with a cryostat and mounted onto gelatin-coated slides.

For staining of IL-1 $\beta$, CD11b and tyrosine hydroxylase $(\mathrm{TH})$, sections were pre-incubated in $5 \%$ normal horse 
serum. The sections were incubated with goat antimouse IL-1 $\beta$ antibody $(1: 100)$ and then were rinsed and incubated with Alexa 546-labeled donkey anti-goat IgG antibody (1:400). After that, they were incubated with rat anti-mouse CD11b antibody (1:100) followed by labeling with Alexa 488-labeled goat anti-rat IgG antibody (1:400). Then they were incubated with polyclonal antiTH antibody (1:1000) followed by labeling with Alexa 350-labeled goat anti-rabbit IgG antibody (1:400).

For staining of 4HNE and NT, following pre-incubation in $5 \%$ normal horse serum sections were incubated with rabbit anti-4HNE antibody (1:500) or rabbit anti-NT antibody (1:500) followed by labeling with Alexa 546-labeled goat anti-rabbit IgG antibody (1:400) and then incubated with 4',6-diamidino-2-phenylindole (DAPI) solution (1:10000) to stain the nuclei.

For staining of $\alpha$-synuclein, following pre-incubation in $5 \%$ normal goat serum, sections were incubated with monoclonal anti- $\alpha$-synuclein antibody(1:500) followed by labeling with Alexa 546-labeled goat anti-mouse IgG antibody (1:400). Then they were incubated with polyclonal anti-TH antibody (1:1000), followed by Alexa 488-labeled goat anti-rabbit IgG antibody (1:400) and DAPI solution. Labeling was imaged with a fluorescence microscope (Olympus AX-70; Olympus, Tokyo, Japan).

For $\mathrm{TH}$ immunostaining using diaminobenzidine, the mice were sacrificed $6 \mathrm{hr}$ after the final injection of the subacute treatment. Slice was prepared as presented above. Slice sections were pre-incubated in 5\% normal goat serum after endogenous peroxidase blocking by 0.1 M PB containing $0.3 \% \mathrm{H}_{2} \mathrm{O}_{2}$ and incubated with polyclonal anti-TH antibody (1:1000). The sections were rinsed and incubated with biotinylated horse anti-rabbit IgG (1:1000). Then they were incubated in an avidinbiotin complex solution followed by diaminobenzidine (DAB kit, Vector, Burlingame, CA).

Fluoro-Jade $B$ staining was used to detect neurodegenerative cells [22]. Sections were fixed with $4 \%$ paraformaldehyde solution for $20 \mathrm{~min}$. After washing twice with PBS and once with water, the sections were immersed in $0.06 \% \mathrm{KMnO}_{4}$ for 15 min and then rinsed three times with purified water. Fluoro-Jade B solution $(0.01 \%$ Fluoro-Jade B: $0.1 \%$ acetic acid $=1: 19)$ was applied for $30 \mathrm{~min}$ at room temperature and then rinsed off with purified water, four times. The sections were dried with cold air and immersed three times in xylene for $2 \mathrm{~min}$. One drop of marinol was put on top and a cover was placed on them. Labeling was imaged with a fluorescence microscope (Olympus AX-70; Olympus, Tokyo, Japan).

\section{Gene expression}

The mice were decapitated $6 \mathrm{hr}$ after the acute PBS or LPS injection or $6 \mathrm{hr}$ after the final PBS or LPS injection of the subacute treatment. The midbrains were dissected according to the method of Glowinski and Iversen [23] and stored at $-80^{\circ} \mathrm{C}$ until use. Total RNA was extracted using the QIAGEN RNeasy Lipid Tissue Mini kit (QIAGEN, Hilden, Germany). Real-time RT-PCR was carried out using QuantiTect SYBR Green RT-PCR system (QIAGEN). Primers for IL-1 $\beta$, TNF $\alpha$, TH and glyceraldehyde 3-phosphate dehydrogenase (GAPDH) were prepared by QuantiTect Primer Assays (QIAGEN). The amplification conditions were 40 cycles at $94^{\circ} \mathrm{C}$ for $15 \mathrm{~s}$, $55^{\circ} \mathrm{C}$ for $30 \mathrm{~s}$ and $72^{\circ} \mathrm{C}$ for $30 \mathrm{~s}$. Quantitative data were obtained from the relative standard curve. mRNA expression was normalized using GAPDH as an endogenous control.

\section{Statistical analysis}

Immunostaining in the substantia nigra pars compact (SNC) was quantified by counting positively stained cells. The number of positively stained cells in four brain sections was counted and averaged (cells $/ \mathrm{mm}^{2}$ ). The statistical analysis used the Mann-Whitney test for the immunostaining, behavioral and gene expression data.

\section{Results}

\section{Activation of the microglia after lipopolysaccharide} treatment

An experiment was conducted to determine whether the microglia was activated by acute LPS treatment $(5 \mu \mathrm{g} /$ $2 \mu \mathrm{L}$ /injection). There were many $\mathrm{TH}$ antibody-labeled dopaminergic neurons in the SNC. Immunohistochemical analysis revealed no IL- $1 \beta$ immunoreactivity in the SNC from mice treated with PBS (Figure 1A). In contrast, cells with strong immunoreactivity for IL- $1 \beta$ were observed $6 \mathrm{hr}$ after the LPS injection. To identify the cells expressing IL-1 $\beta$, a triple-label immunohistochemical study was performed for IL- $1 \beta$, CD11b and TH. IL- $1 \beta$ immunopositive cells were co-localized with cells immunoreactive to CD11b. In the early stage of activation, LPS induced an increase in IL- $1 \beta$ signals in the microglia, the shape of which remained in the ramified form $6 \mathrm{hr}$ after the acute LPS treatment. The gene expressions of IL- $1 \beta$ and TNF $\alpha$ in the midbrain were still noticeably higher 6 $\mathrm{hr}$ after the acute LPS treatment (Figure 1B).

We demonstrated the long-term activation of the microglia after the subacute treatment with LPS for 5 days (Figure 2). In the SN of mice injected with PBS, the majority of the CD11b immunopositive cells exhibited a resting or ramified state (Figure 2A, upper rows). After the subacute LPS treatment, the CD11b-immunopositive cells were activated, as indicated by an increased number of cells (Figure 2B) as well as a change in their morphology to a round and blunt shape (amoeboid form, Figure 2A, lower rows). The CD11b-immunopositive cells had an activated phenotype. These results suggest that the subacute 


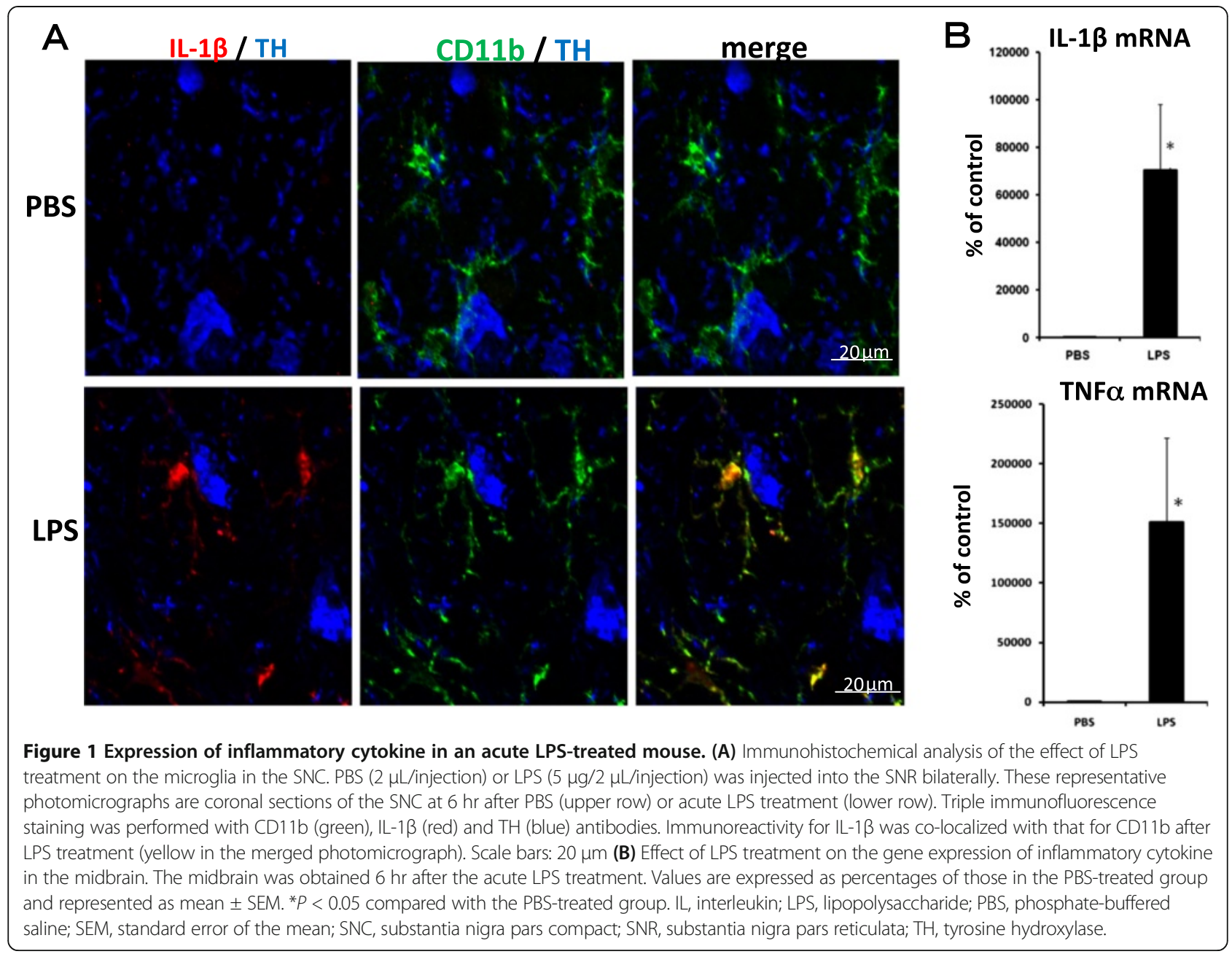

LPS treatment caused a sustained activation of the microglia, resulting in an increase in the number of microglial cells and morphological changes.

\section{Detection of oxidative stress}

$4 \mathrm{HNE}$ is a product of lipid peroxidation and its increased production is a biomarker of oxidative stress. The number of 4HNE-positive cells in the SNC was significantly increased $6 \mathrm{hr}$ after the final LPS injection (Figure 3A,B, upper row). NT is an indicator of cell damage, the activation of inflammation and NO production [39]. NT-immunopositive cells were seen to increase up to fourfold $6 \mathrm{hr}$ after the final LPS injection compared with the PBS-treated group (Figure 3A,B, lower row). These results suggest that oxidative stress was induced in the SNC by the subacute LPS treatment.

\section{Detection of cell death using Fluoro-Jade B and tyrosine hydroxylase immunostaining}

Cell death was seen in coronal sections of the $\mathrm{SN}$ using Fluoro-Jade B staining (Figure 4A). Six hr after the final injection, degenerating neurons stained with Fluoro-Jade $\mathrm{B}$ were not observed. However, 21 and 30 days after the final injection, Fluoro-Jade B-positive cells were detected in a similar manner as observed in the positive control specimens prepared after a traumatic cortical brain injury. Furthermore, the number of $\mathrm{TH}$ antibody-labeled dopaminergic neurons in the SNC decreased $6 \mathrm{hr}$ after the final LPS injection (Figure 4B). These results indicate that delayed cell death was induced in the SNC by the subacute LPS treatment.

a-synuclein expression in lipopolysaccharide-treated mice We performed an immunohistochemical analysis to see if there was any $\alpha$-synuclein protein in the SNC (Figure 5). $\alpha$-synuclein-immunopositive cells were observed 30 days after the final LPS injection (Figure 5A). $\alpha$-synuclein gene expression in the midbrain area was unchanged $6 \mathrm{hr}$ after the final LPS treatment compared with its expression in the PBS-treated group (data not shown). However, 30 days after the final LPS injection, $\alpha$-synuclein gene expression 


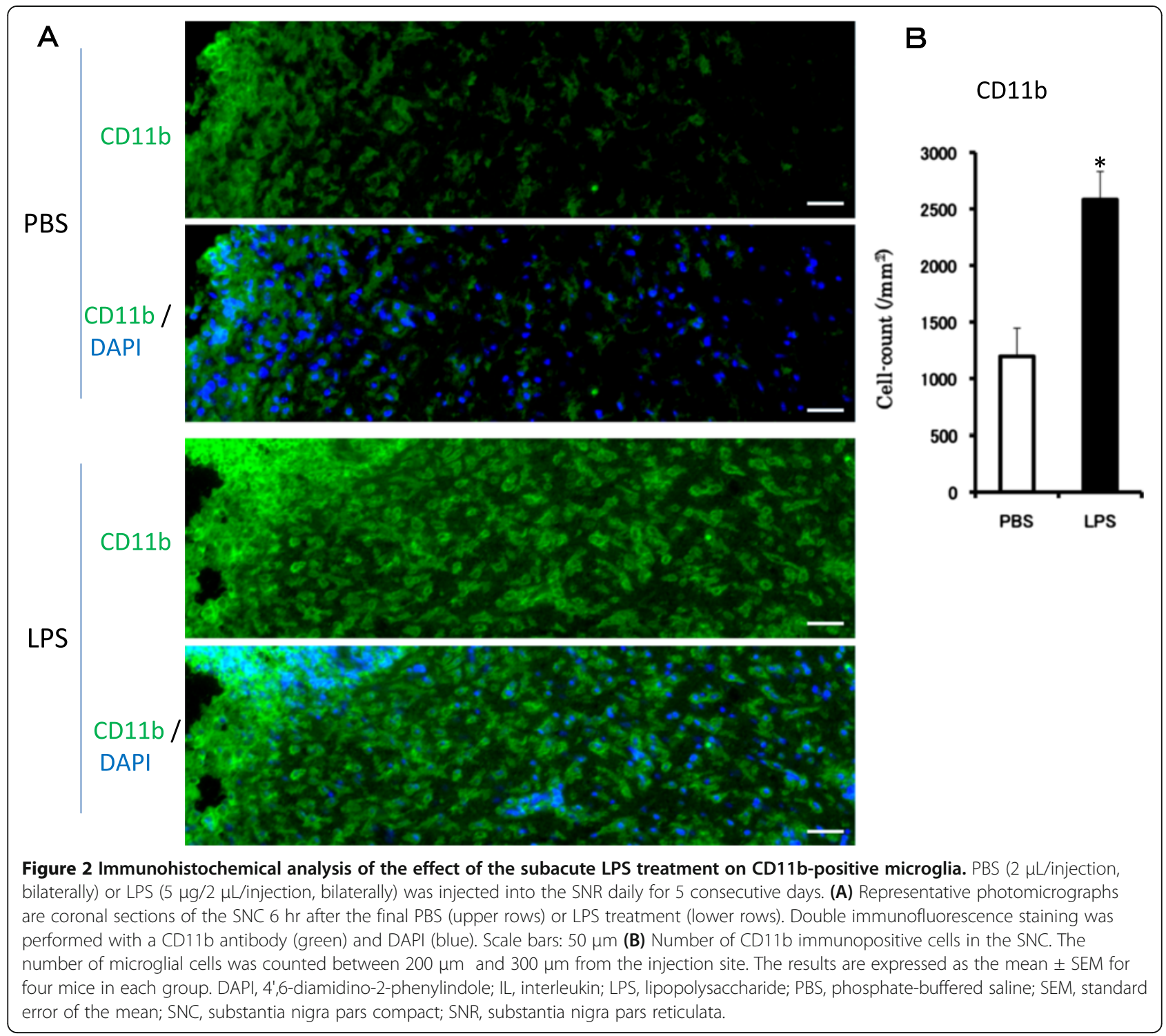

was significantly increased to $170 \%$ of that for the PBStreated group (Figure 5B).

\section{Assessment of animal behavior using the rotarod test}

Behavioral tests were performed $2 \mathrm{hr}$ and 8,15 and 22 days after the final LPS injection. The latency of the mice increased during the trial (Figure 6). In wild-type mice, LPS produced a lower latency to fall off, which was significant 15 days and 22 days after the final injection. These results suggest that the LPS treatment resulted in behavioral impairment of the motor function. We used genetically modified animals to determine whether the pro-inflammatory cytokine was involved in the LPS-induced behavioral deficit. The behavioral tests were performed with the IL- $1 \alpha / \beta$ double $\mathrm{KO}$ and TNF $\alpha$ KO mice treated either with PBS or LPS. The latency of the IL-1 KO and TNF $\alpha$ KO mice also increased during the trial, like the wild-type mice (Figure 6). TNF $\alpha \mathrm{KO}$ mice treated with LPS had a significantly lower latency to fall off $2 \mathrm{hr}, 8$ days and 22 days after the final LPS injection. However, there was no difference between the PBS and LPS treatments for the IL-1 KO mice. These results suggest that the LPS treatment caused impairment of the motor function in the wild-type and TNF $\alpha \mathrm{KO}$ mice, but not in the IL-1 KO mice.

Tyrosine hydroxylase gene expression in wild-type, TNFa and IL-1 KO mice

We analyzed the gene expression of $\mathrm{TH}$, a marker for dopaminergic and noradrenergic neurons, in the wild-type, TNF $\alpha$ and IL-1 KO mice $6 \mathrm{hr}$ after the final LPS injection. The subacute LPS treatment significantly suppressed TH 


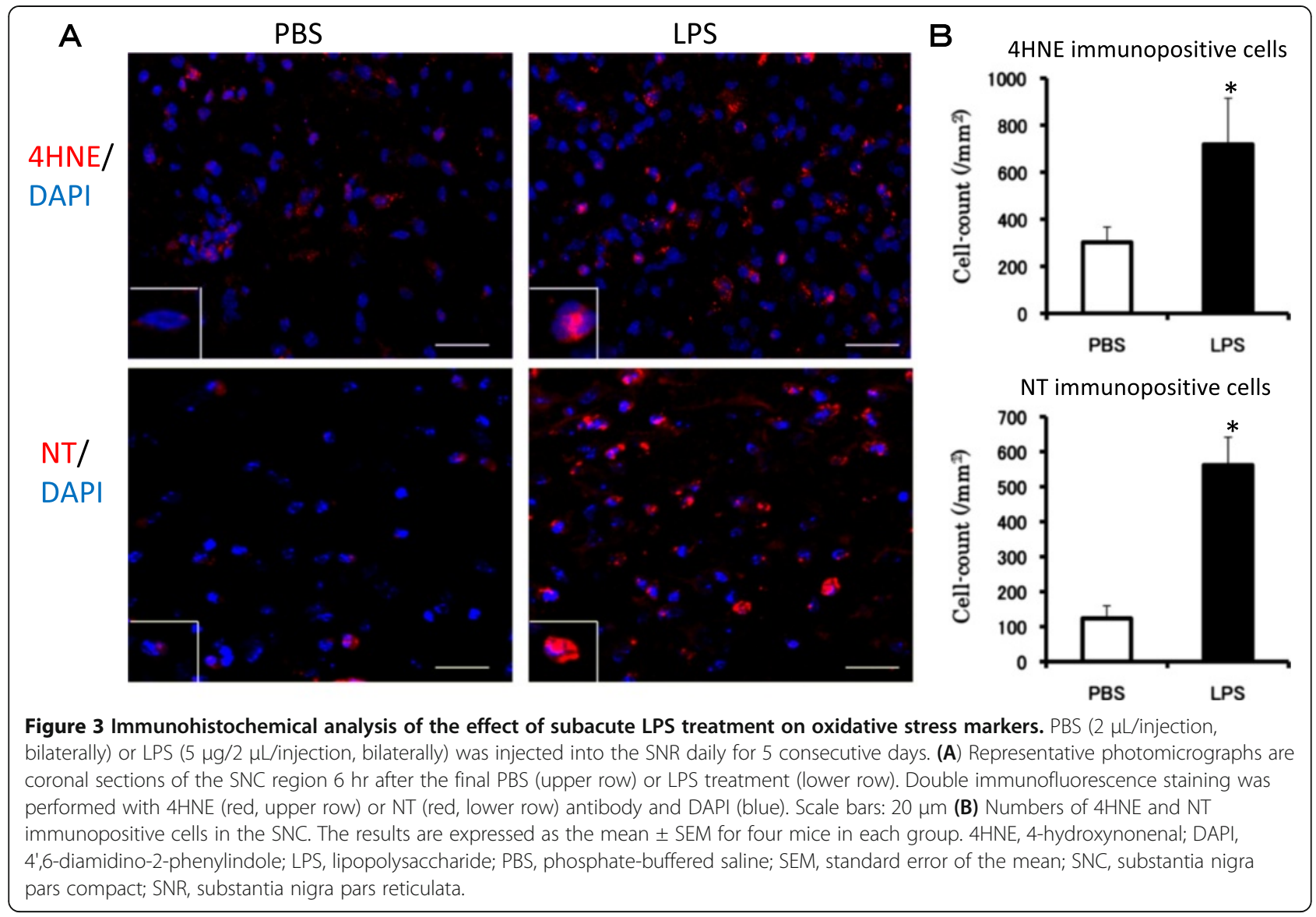

gene expression in the wild-type and TNF $\alpha \mathrm{KO}$ mice, but not IL-1 KO mice (Figure 7). These results for TH expression are in agreement with those obtained from the behavior tests.

\section{Discussion}

In the present study, we investigated whether in vivo activation of the microglia leads to impaired neuronal function and found that LPS-induced functional outcomes in terms of decreased motor performance correlated well with changes in immunohistochemistry and gene expression.

PD models have been created by exposing animals to toxins such as MPTP [14-16] and 6-OHDA [17]. These toxins have been demonstrated to cause PD-like symptoms with massive losses of dopaminergic neurons in the SN. These toxins are selectively taken up by dopaminergic neurons via the dopamine transporter and cause neuronal cell death without $\alpha$-synuclein aggregation. In contrast, neuronal cell death is not believed to be the first event in the development of PD. What triggers PD in humans has not been determined. Therefore, these toxins do not induce changes that completely mimic PD-like pathology.
We chose LPS to induce microglial activation and neuronal inflammation in the SN of mice. In the LPSinduced inflammation model, dopaminergic neurons were not directly injured by the endotoxin, which may cause deterioration of neurons via the microglia. The present study indicated that LPS treatment caused the activation of the microglial cells that produce IL- $1 \beta$ and TNF $\alpha$ as well as changes in microglial morphology. These findings are comparable to those previously reported for our rat and mouse models [5,18], in which LPS injected into the hippocampus induced learning and memory deficits. TNF $\alpha$ and IL- $1 \beta$ are elevated in patients with PD [24-26] and animal models [27,28]. The activated microglia increases the secretion of pro-inflammatory cytokines and activates pro-oxidant enzymes such as nicotinamide adenine dinucleotide phosphate oxidase and inducible nitric oxide synthase (iNOS), resulting in the production of reactive oxygen species (ROS) and nitric oxide $[29,30]$.

Oxidative stress contributes to the neurodegenerative process in $\mathrm{AD}$ and $\mathrm{PD}[31,32]$. PD is characterized by the selective loss of dopaminergic neurons in the $\mathrm{SN}$, and dopamine has been suggested to be the main endogenous toxin causing oxidative stress in the genesis of PD [33]. 


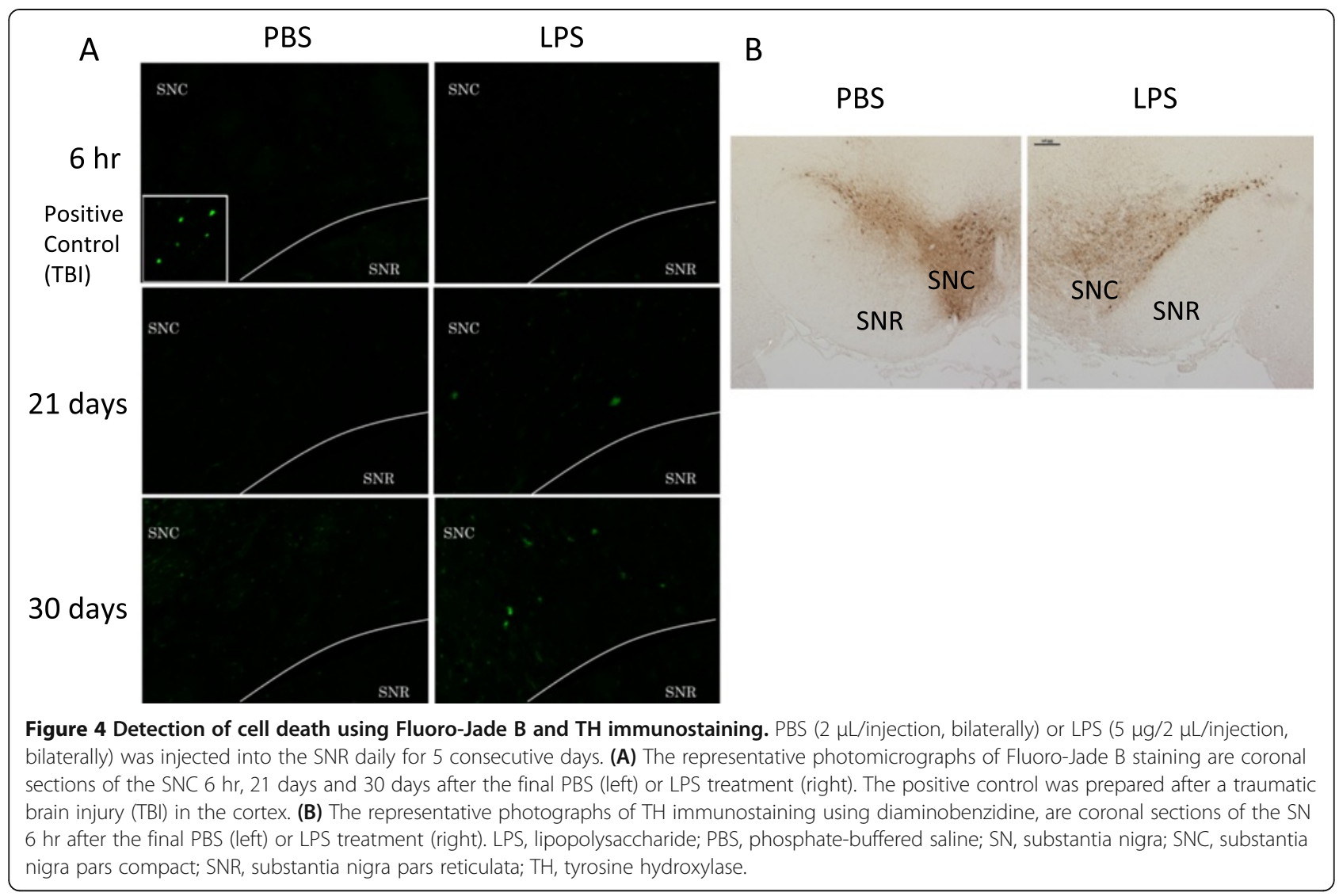

Dopaminergic neurons are vulnerable to oxidative stress. Dopamine is easily oxidized by molecular oxygen to produce ROS such as superoxide anions and hydrogen peroxide and forms aminochrome via dopamine o-quinone [34]. Iron accumulates in the SN of patients with PD [35]. Auto-oxidation of dopamine is stimulated by iron in patients with PD, which causes the degeneration of dopaminergic neurons by enhancing oxidative stress [34]. Levels of free and protein-bound 4HNE, a toxic aldehyde produced by the peroxidation of fatty acids, were significantly elevated in the ventricular fluid of patients with $\mathrm{AD}$ [36] and a PD animal model [37]. 4HNE induces apoptosis with caspase activation and DNA fragmentation [38]. In our LPS-induced animal model, we detected an increase in the number of cells immunopositive for $4 \mathrm{HNE}$, which could be involved in neuronal cell death. We also observed that LPS increased the number of cells immunopositive for NT, which has been identified as an indicator of cell damage and inflammation as a result of the production of NO and oxidative stress [39]. LPS stimulates the induction of iNOS and its product NO reacts with superoxide to produce peroxynitrite and eventually nitration of proteins, which might contribute to disturbing protein functions resulting in the pathological processes seen during neurodegeneration. $\alpha$-synuclein is a major component of Lewy bodies, a pathological hallmark of PD, and is involved in neurodegeneration [40]. It has been reported that LPS stimulates the production of $\alpha$-synuclein in the $\mathrm{SN}$ of rats [41]. The present study demonstrated that there was $\alpha$-synuclein gene expression and cell death 22 and 30 days after the final LPS injection, respectively. However, the changes in animal behavior started just after the final LPS injection, suggesting that impairment of the motor function appears before cell death. These results suggest that the subacute injection of LPS into the SNR induces PD-like pathogenesis and symptoms in mice, which mimic the progressive changes of PD including the aggregation of $\alpha$-synuclein that causes the dysfunction of motor performance. Therefore, a subacute LPS treatment could be a novel regimen to create animal models of PD.

We did not determine the type of cells that took part in the delayed cell death in this study. It is well known that $80 \%$ of neurons in the SNC are dopaminergic. Numbers of TH-immunopositive cells decreased $6 \mathrm{hr}$ after the LPS final injection. Therefore, it is suggested that Fluoro-Jade B-stained cells are dopaminergic neurons in the SNC.

Several reports attest the involvement of IL-1 in neurodegenerative diseases. Increased iNOS immunoreactivity, 


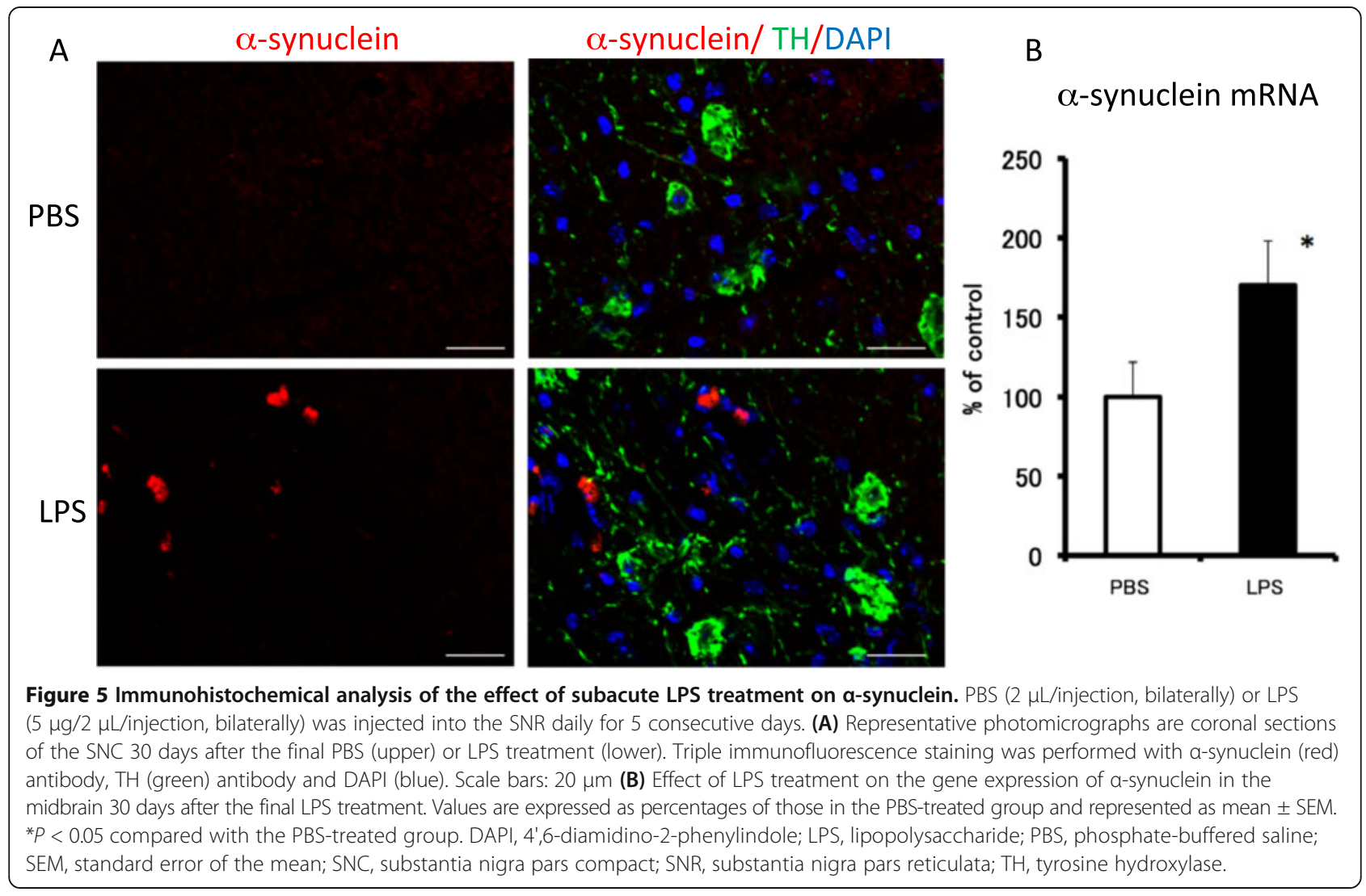

which is normally observed after brain ischemia, is diminished in IL-1 KO mice. These mice exhibit markedly reduced neuronal loss and apoptotic cell death when they experience a transient cardiac arrest [42]. In a spinal cord injury model, the size of the lesion area decreased in IL-1
KO mice compared with wild-type mice [43]. We previously demonstrated that LPS-induced deficits of learning and memory did not occur for IL-1 KO mice [18]. These findings indicate that IL-1 plays an important role in neurodegenerative disorders in which a neuronal dysfunction

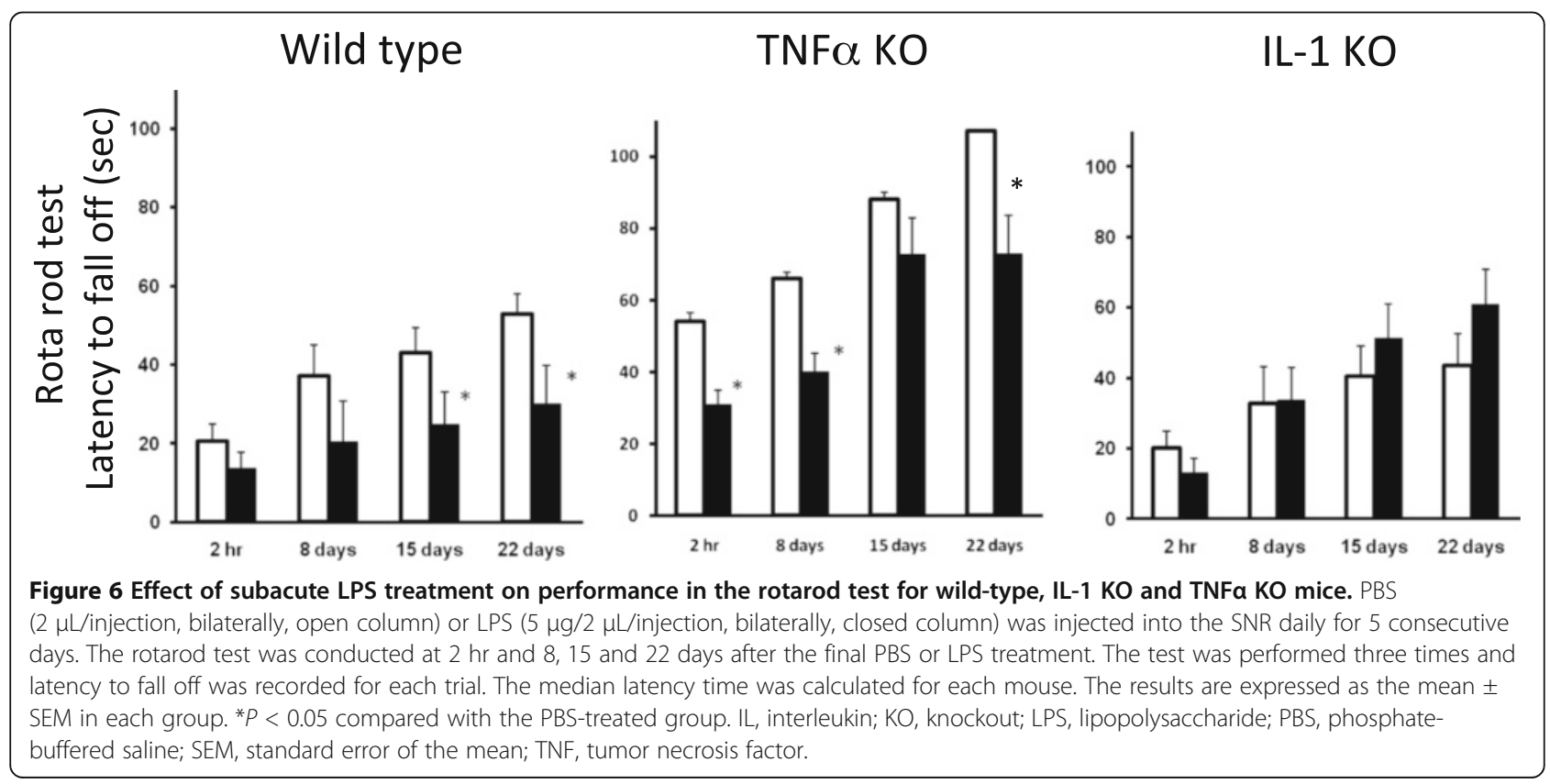




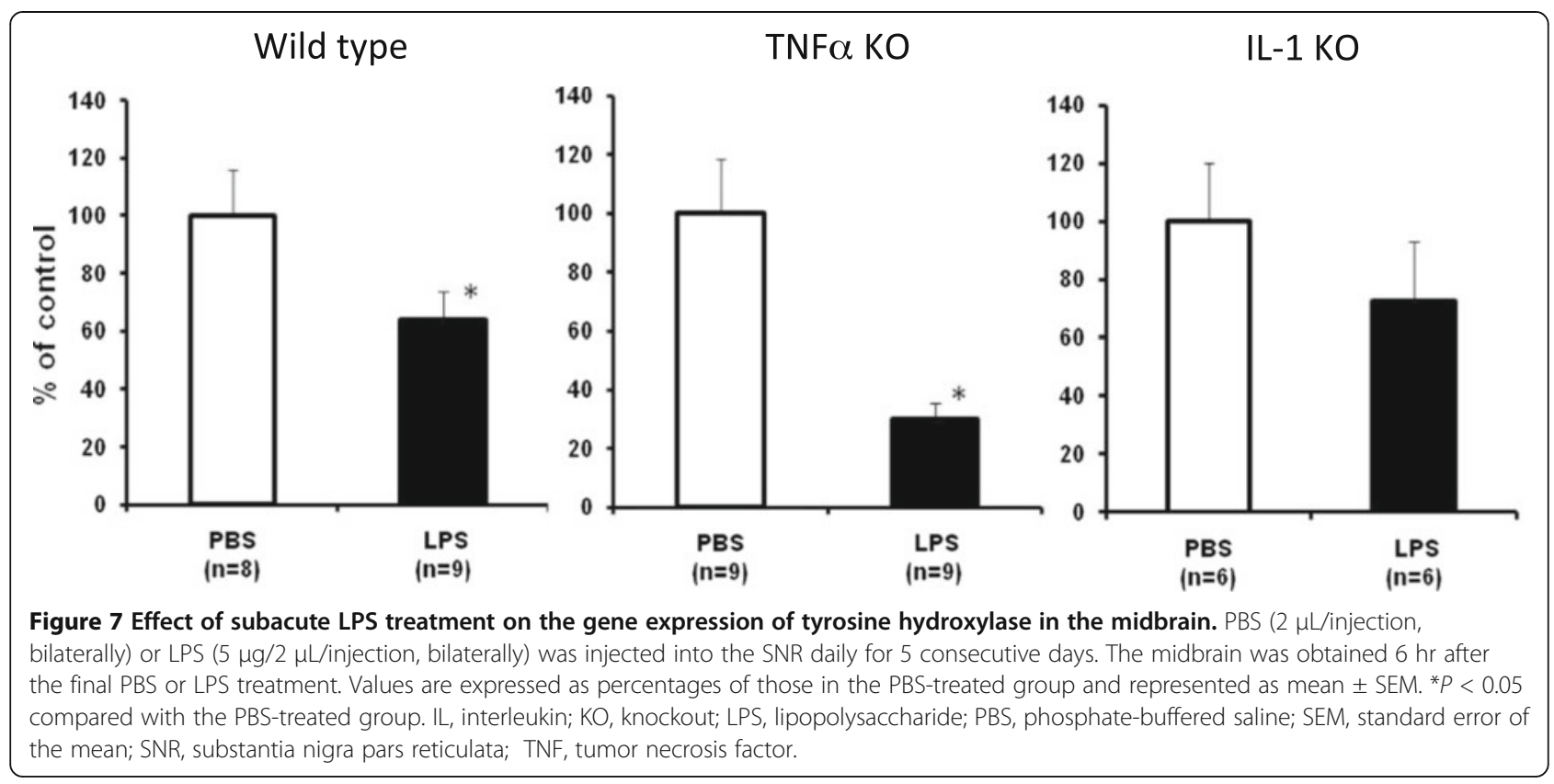

is associated with the activation of the microglia and increased IL-1 expression.

The present study demonstrated that behavioral deficits do not occur following a subacute LPS treatment in IL-1 KO mice. TH gene expression, the late-limiting enzyme for dopamine synthesis, was attenuated by the LPS treatment in wild-type and TNF $\alpha \mathrm{KO}$ mice, but not in IL-1 KO mice. Impairment of the motor function was accompanied by an alteration of $\mathrm{TH}$ gene expression. It appears that increased IL-1 expression in the early stage of PD may trigger microglial activation and may be involved in neurodegeneration. Thus, neuroinflammation including an increase of IL-1 levels and augmentation of its signaling pathway may contribute to the dopaminergic dysfunction. If we had checked dopamine levels, we may have found direct evidence for dopaminergic neuron attenuation and motor dysfunction. We will check dopamine levels in the following study. Our present results suggest that IL-1 plays an important role in mediating LPS-induced functional changes of motor performance. However, the precise mechanism by which microglial activation occurs remains to be determined.

\section{Conclusions}

The findings presented in this study provide evidence that activation of the microglia by LPS causes functional changes such as dopaminergic neuron attenuation in an IL-1-dependent manner, resulting in PD-like behavioral impairment. The LPS-induced animal model for PD could be a useful tool for clarifying mechanisms underlying the neurodegenerative disease and, therefore, should be evaluated further.

\section{Abbreviations}

4HNE: 4-hydroxynonenal; 6-OHDA: 6-hydroxydioamine; AD: Alzheimer's disease; DAPI: 4',6-diamidino-2-phenylindole; GAPDH: Glyceraldehyde 3phosphate dehydrogenase; GFAP: Glial fibrillary acidic protein; IL: Interleukin; iNOS: inducible nitric oxide synthase; KO: Knockout; LPS: Lipopolysaccharide; MPTP: 1-methyl 4-phenyl 1,2,3,6,-tetrahydropyridine; NT: Nitrotyrosine; PB: Phosphate buffer; PBS: Phosphate-buffered saline; PD: Parkinson's disease; ROS: Reactive oxygen species; RT-PCR: Real-time polymerase chain reaction; SEM: Standard error of the mean; SN: Substantia nigra; SNC: Substantia nigra pars compact; SNR: Substantia nigra pars reticulata; TH: Tyrosine hydroxylase; TNF: Tumor necrosis factor.

\section{Competing interests}

The authors declare that they have no competing interests.

\section{Authors' contributions}

ST designed the study, established the protocols and drafted the manuscript. Al carried out the experiments and the statistical analysis. $\mathrm{HO}$ helped to establish the protocols and participated in the data analysis. SS and TY participated in the data analysis and helped to draft the manuscript. SN coordinated the experiments and co-wrote the manuscript. All authors read and approved the final manuscript.

\section{Acknowledgements}

This work was supported in part by a Showa University grant for innovative collaborative research projects, a MEXT (the Japanese Ministry of Education, Culture, Sports, Science and Technology)-supported program of the Strategic Research Foundation at Private Universities for 2008 to 2012, and the High-Tech Research Center Project for Private Universities, which matched the funding from MEXT for 2010 to 2012. We also thank Dr. Z Cai for English proofreading and Ms. A Kaizaki for technical assistance.

\section{Author details}

'Department of Pharmacology, Toxicology and Therapeutics, Division of Toxicology, School of Pharmacy, Showa University, 1-5-8 Hatanodai, Shinagawa-ku, Tokyo 142-8555, Japan. ${ }^{2}$ Department of Anatomy, School of 
Medicine, Showa University, 1-5-8 Hatanodai, Shinagawa-ku, Tokyo 142-8555, Japan.

Received: 2 August 2013 Accepted: 7 November 2013 Published: 1 December 2013

\section{References}

1. Quan N, Sundar SK, Weiss JM: Induction of interleukin-1 in various brain regions after peripheral and central injections of lipopolysaccharide. J Neuroimmunol 1994, 49:125-134.

2. Gayle DA, Ling Z, Tong C, Landers T, Lipton JW, Carvey PM: Lipopolysaccharide (LPS)-induced dopamine cell loss in culture: roles of tumor necrosis factor- $a$, interleukin- $1 \beta$, and nitric oxide. Brain Res Dev 2002, 133:27-35.

3. Gasparini L, Ongini E, Maucci R, Rosi S, Ronchetti D, Wenk G, McGann K, Hauss-Wegrzyniak B: Attenuation of chronic neuroinflammation by a nitric oxide releasing derivative of the antioxidant ferulic acid. J Neurochem 2004, 89:484-493.

4. Fogal B, Hewett JA, Hewett $S$ J: Interleukin-1 $\beta$ potentiates neuronal injury in a variety of injury models involving energy deprivation. J Neuroimmunol 2005, 161:93-100.

5. Tanaka S, Ide M, Shibutani T, Ohtaki H, Numazawa S, Shioda S, Yoshida T: Lipopolysaccharide-induced microglial activation induces learning and memory deficits without neuronal cell death in rats. J Neurosci Res 2006 83:557-566.

6. McGeer PL, Itagaki S, Boyes BE, McGeer EG: Reactive microglia are positive for HLA-DR in the substantia nigra of Parkinson's and Alzheimer's disease brains. Neurology 1988, 38:1285-1291.

7. Dickson DW, Lee SC, Mattiace LA, Yen SH, Brosnan C: Microglia and cytokines in neurological disease, with special reference to AIDS and Alzheimer's disease. Glia 1993, 7:75-83.

8. Bo L, Monk S, Kong PA, Nyland H, Pardo CA, Trapp BD: Detection of MHC class II antigens on macrophages and microglia, but not on astrocytes and endothelia in active multiple sclerosis lesions. J Neuroimmunol 1994 51:135-146.

9. Chen H, Jacobs E, Schwarzschild MA, McCullough ML, Calle EE, Thun MJ, Ascherio A: Nonsteroidal antiinflammatory drug use and the risk for Parkinson's disease. Ann Neurol 2005, 58:963-967.

10. Wahner AD, Bronstein JM, Bordelon YM, Ritz B: Nonsteroidal anti-inflammatory drugs may protect against Parkinson disease. Neurology 2007, 69:1836-1842.

11. Rees K, Stowe R, Patel S, Ives N, Breen K, Clarke CE, Ben-Shlomo Y: Nonsteroidal anti-inflammatory drugs as disease-modifying agents for Parkinson's disease: evidence from observational studies. Cochrane Database Syst Rev 2011, 11, CD008454.

12. Lindvall $\mathrm{O}$, Ekdahl $\mathrm{CT}$, Claasen $\mathrm{JH}$, Bonde $\mathrm{S}$, Kokaia Z, Lindvall $\mathrm{O}$ : Inflammation is detrimental for neurogenesis in adult brain. Proc Nat Acad Sci USA 2003, 100:13632-13637.

13. Olanow CW, Tatton WG: Etiology and pathogenesis of Parkinson's disease. Annu Rev Neurosci 1999, 22:123-144.

14. Heikkila RE, Hess A, Duvoisin RC: Dopaminergic neurotoxicity of 1-methyl4-phenyl-1,2,5,6-tetrahydropyridine in mice. Science 1984, 224:1451-1453.

15. Dauter W, Przedborski S: Parkinson's disease: mechanisms and models. Neuron 2003, 39:889-909.

16. Fornai F, Schluter OM, Lenzi P, Gesi M, Ruffoli R, Ferrucci M, Lazzeri G, Busceti CL, Pontarelli F, Battaglia G, Pellegrini A, Nicoletti F, Ruggieri S, Paparelli A, Sudhof TC: Parkinson-like syndrome induced by continuous MPTP infusion: convergent roles of the ubiquitin-proteasome system and a-synuclein. Proc Natl Acad Sci USA 2005, 102:3413-3418.

17. Zeng BY, Dass B, Owen A, Rose S, Cannizzaro C, Tel BC, Jenner P: 6hydroxydopamine lesioning differentially affects a-synuclein mRNA expression in the nucleus accumbens, striatum and substantia nigra of adult rats. Neurosci Lett 2002, 322:33-36.

18. Tanaka S, Kondo H, Kanda K, Ashino T, Nakamachi T, Sekikawa K, Iwakura Y, Shioda S, Numazawa S, Yoshida T: Involvement of interleukin-1 in lipopolysaccaride-induced microglial activation and learning and memory deficits. J Neurosci Res 2011, 89:506-514.

19. Horai R, Asano M, Sudo K, Kanuka H, Suzuki M, Nishihara M, Takahashi M, Iwakura Y: Production of mice deficient in genes for interleukin (IL)-1a IL-1 $\beta, I L 1 \alpha / \beta$, and IL-1 receptor antagonist shows that IL-1 $\beta$ is crucial in turpentine-induced fever development and glucocorticoid secretion. J Exp Med 1998, 187:1463-1475.
20. Tagawa $Y$, Sekikawa K, Iwakura $Y$ : Suppression of concanavalin A-induced hepatitis in IFN-gamma(-/-) mice, but not in TNF-alpha(-/-) mice: role for IFN-gamma in activating apoptosis of hepatocytes. J Immunol 1997, 159:1418-1428.

21. Ohtaki H, Funahashi H, Dohi K, Oguro T, Horai R, Asano M, Owakura Y, Yin L, Matsunaga M, Goto N, Shioda S: Suppression of oxidative neuronal damage after transient middle cerebral artery occlusion in mice lacking interleukin-1. Neurosci Res 2003, 45:313-324.

22. Schmued LC, Albertson C, Slikker W Jr: Fluoro-Jade: a novel fluorochrome for the sensitive and reliable histochemical localization of neuronal degeneration. Brain Res 1997, 751:37-46.

23. Glowinski J, Iversen LL: Regional studies of catechol-amines in the rat brain. I. The disposition of [3H[norepinephrine, [3H]dopamine and $[3 \mathrm{H}]$ dopa in various regions of the brain. J Neurochem 1966, 13:655-669.

24. Lindqvist D, Kaufman E, Brundin L, Hall S, Surova Y, Hansson O: Non-motor symptoms in patients with Parkinson's disease - correlations with inflammatory cytokines in serum. PLos One 2012, 7:e47387.

25. Boka G, Anglade P, Wallach D, Javoy-Agid F, Agid Y, Hirsch EC: Immunocytochemical analysis of tumor necrosis factor and its receptors in Parkinson's disease. Neurosci Lett 1994, 172:151-154.

26. Mogi $M$, Harada $M$, Kondo $T$, Riederer $P$, Inagaki H, Minami M, Nagatsu $T$ : Interleukin-1 $\beta$, interleukin-6, epidermal growth factor and transforming growth factor-alpha are elevated in the brain from Parkinsonian patients. Neurosci Lett 1994, 180:147-150.

27. Poot Godoy MC, Tarelli R, Ferrari CC, Sarchi MI, Pitossi FJ: Central and systemic IL-1 exacerbates neurodegeneration and motor symptoms in a model of Parkinson's disease. Brain 2008, 131:1880-1894.

28. Koprich JB, Reske-Nielsen C, Mithal P, Isacson O: Neuroinflammation mediated by IL- $1 \beta$ increases susceptibility of dopamine neurons to degeneration in an animal model of Parkinson's disease. J Neuroinflamm 2008, 5:8.

29. Zhang W, Wang T, Pei Z, Miller DS, Wu X, Block ML, Wilson B, Zhang W, Zhou Y, Hong JS, Zhang J: Aggregated a-synuclein activates microglia: a process leading to disease progression in Parkinson's disease. FASEB 2005, 19:533-542.

30. Li P, Kaur C, Lu J, Sivakumar V, Dheen ST, Ling EA: Expression of cyclooxygenase-2 and microsomal prostaglandin-E synthase in amoeboid microglial cells in the developing brain and effects of cyclooxygenase-2 neutralization on BV-2 microglial cells. J Neurosci Res 2010, 88:1577-1594.

31. Jenner P: Oxidative stress in Parkinson's disease. Ann Neurol 2003, 53:S26-S38

32. Gao HM, Zhou H, Hong JS: NADPH oxidases: novel therapeutic targets for neurodegenerative diseases. Trends in Pharmacol Sci 2012, 33:295-303.

33. Jenner $\mathrm{P}$, Olanow CW: Oxidative stress and the pathogenesis of Parkinson's disease. Neurology 1996, 47:S161-S170.

34. Izumi Y, Sawada H, Yamamoto N, Kume T, Katsuki H, Shimohama S, Akaike A: Iron accelerates the conversion of dopamine-oxidized intermediates into melanin and provides protection in SH-SY5Y cells. J Neurosci Res 2005, 82:126-137.

35. Sofic E, Paulus W, Jellinger K, Riederer P, Youdim MB: Selective increase of iron in substantia nigra zona compacta of Parkinsonian brains. J Neurochem 1991, 56:978-982.

36. Lovell MA, Ehmann WD, Mattson MP, Markesbery WR: Elevated 4hydroxynonenal in ventricular fluid in Alzheimer's disease. Neurobiol Aging 1997, 18:457-461.

37. Fujita K, Seike T, Yutsudo N, Ohno M, Yamada H, Yamaguchi H, Sakumi K, Yamakawa Y, Kido MA, Takaki A, Katafuchi T, Tanaka Y, Nakabeppu Y, Noda $M$ : Hydrogen in drinking water reduces dopaminergic neuronal loss in the 1-methyl-4-phenyl-1236-tetrahydropyridine mouse model of Parkinson's disease. PLoS One 2009, 4:e7247.

38. Liu W, Kato M, Akhand AA, Hayakawa A, Suzuki H, Miyata T, Kurokawa K, Hotta Y, Ishikawa N, Nakashima I: 4-hydroxynonenal induces a cellular redox, status-related activation of the caspase cascade for apoptotic cell death. J Cell Sci 2000, 113:635-641.

39. Ding M, St Pierre BA, Parkinson JF, Medberry P, Wong JL, Rogers NE, Ignarro LJ, Merrill JE: Inducible nitric-oxide synthase and nitric oxide production in human fetal astrocytes and microglia. J Biol Chem 1997, 272:11327-11335.

40. Yamada T, McGeer PL, McGeer EG: Lewy bodies in Parkinson's disease are recognized by antibodies to complement proteins. Acta Neuropathol 1992, 84:100-104. 
41. Choi DY, Liu M, Hunter RL, Cass WA, Pandya JD, Sullivan PG, Shin EJ, Kim HC, Gash DM, Bing G: Striatal neuroinflammation promotes Parkinsonism in rats. Plos One 2009, 4:e5482.

42. Mizushima H, Zhou CJ, Dohi K, Horai R, Asano M, Iwakura Y, Hirabayashi T, Arata S, Nakajo S, Takaki A, Ohtaki H, Shioda S: Reduced postischemic apoptosis in the hippocampus of mice deficient in interleukin-1. J Comp Neurol 2002, 448:203-216.

43. Sato A, Ohtaki $H$, Tsumuraya $T$, Song $D$, Ohara $K$, Asano M, Iwakura $Y$, Atsumi T, Shioda S: Interleukin-1 participates in the classical and alternative activation of microglia/macrophages after spinal cord injury. J Neuroinflamm 2012, 9:65.

doi:10.1186/1742-2094-10-143

Cite this article as: Tanaka et al: Activation of microglia induces

symptoms of Parkinson's disease in wild-type, but not in IL-1 knockout mice. Journal of Neuroinflammation 2013 10:143.

\section{Submit your next manuscript to BioMed Central and take full advantage of:}

- Convenient online submission

- Thorough peer review

- No space constraints or color figure charges

- Immediate publication on acceptance

- Inclusion in PubMed, CAS, Scopus and Google Scholar

- Research which is freely available for redistribution 